\title{
Size dependent translocation and fetal accumulation of gold nanoparticles from maternal blood in the rat
}

Manuela Semmler-Behnke ${ }^{5,1}$, Jens Lipka ${ }^{1}$, Alexander Wenk' ${ }^{1}$ Stephanie Hirn ${ }^{6,1}$, Martin Schäffler ${ }^{1}$, Furong Tian ${ }^{7,1}$, Günter Schmid ${ }^{3}$, Günter Oberdörster ${ }^{2}$ and Wolfgang G Kreyling ${ }^{1,4^{*}}$

\begin{abstract}
Background: There is evidence that nanoparticles (NP) cross epithelial and endothelial body barriers. We hypothesized that gold (Au) NP, once in the blood circulation of pregnant rats, will cross the placental barrier during pregnancy size-dependently and accumulate in the fetal organism by 1. transcellular transport across the hemochorial placenta, 2. transcellular transport across amniotic membranes 3. transport through $\sim 20 \mathrm{~nm}$ wide transtrophoblastic channels in a size dependent manner. The three AuNP sizes used to test this hypothesis are either well below, or of similar size or well above the diameters of the transtrophoblastic channels.

Methods: We intravenously injected monodisperse, negatively charged, radio-labelled $1.4 \mathrm{~nm}, 18 \mathrm{~nm}$ and $80 \mathrm{~nm}$ ${ }^{198} \mathrm{AuNP}$ at a mass dose of 5, 3 and $27 \mu \mathrm{g} / \mathrm{rat}$, respectively, into pregnant rats on day 18 of gestation and in non-pregnant control rats and studied the biodistribution in a quantitative manner based on the radio-analysis of the stably labelled ${ }^{198}$ AuNP after 24 hours.

Results: We observed significant biokinetic differences between pregnant and non-pregnant rats. AuNP fractions in the uterus of pregnant rats were at least one order of magnitude higher for each particle size roughly proportional to the enlarged size and weight of the pregnant uterus. All three sizes of ${ }^{198}$ AuNP were found in the placentas and amniotic fluids with $1.4 \mathrm{~nm}$ AuNP fractions being two orders of magnitude higher than those of the larger AuNP on a mass base. In the fetuses, only fractions of 0.0006 (30 ng) and $0.00004(0.1 \mathrm{ng})$ of $1.4 \mathrm{~nm}$ and $18 \mathrm{~nm}$ AuNP, respectively, were detected, but no $80 \mathrm{~nm}$ AuNP $(<0.000004(<0.1 \mathrm{ng})$ ). These data show that no AuNP entered the fetuses from amniotic fluids within 24 hours but indicate that AuNP translocation occurs across the placental tissues either through transtrophoblastic channels and/or via transcellular processes.
\end{abstract}

Conclusion: Our data suggest that the translocation of AuNP from maternal blood into the fetus is NP-size dependent which is due to mechanisms involving (1) transport through transtrophoblastic channels - also present in the human placenta - and/or (2) endocytotic and diffusive processes across the placental barrier.

Keywords: Gold nanoparticles, Accumulation in rat fetus, Placenta, Transtrophoblastic channel, Amniotic membrane

\footnotetext{
* Correspondence: kreyling@helmholtz-muenchen.de

${ }^{1}$ Institute of Lung Biology and Disease, Helmholtz Zentrum München -

German Research Center for Environmental Health, 85764 Neuherberg/

Munich, Germany

${ }^{4}$ Institute of Epidemiology II, Helmholtz Zentrum München - German

Research Center for Environmental Health, 85764 Neuherberg/Munich,

Germany

Full list of author information is available at the end of the article
}

C Biomed Central

(C) 2014 Semmler-Behnke et al.; licensee BioMed Central Ltd. This is an Open Access article distributed under the terms of the Creative Commons Attribution License (http://creativecommons.org/licenses/by/4.0), which permits unrestricted use,

distribution, and reproduction in any medium, provided the original work is properly credited. The Creative Commons Public Domain Dedication waiver (http://creativecommons.org/publicdomain/zero/1.0/) applies to the data made available in this article, unless otherwise stated. 


\section{Background}

The multiple benefits associated with the increasing manufacturing of nanotechnology based products are met with equally increasing concerns about potential adverse health effects from exposure of consumers to engineered nanoparticles (NP) [1]. These concerns are based on findings from biokinetic studies in humans and experimental animals revealing that NP may enter the body via the respiratory tract or the gastro-intestinal-tract and thereby be distributed throughout the body [1-6]. However, although translocation of NP from the portal of entry across cellular barriers (e.g., alveolo-capillary barrier) has been described, the amount of NP reaching the blood circulation from the primary portal of entry appears to be rather low [5-11]. However, the small fractions of insoluble NP translocating into systemic circulation localize and accumulate in secondary organs such as liver, spleen, heart and others as well as in bone marrow during chronic exposure [12,13]. One of the critical protective barriers is the placenta, providing protection of the unborn from potential toxicants. It is known, though, that the placental barrier function cannot be complete because the fetus requires continuous transfer of glucose and nutrients, including proteins, phospholipids, antibodies, and hormones from the maternal blood circulation [14]. Therefore, even air pollutants, side stream smoke and engineered particulates, after reaching the blood compartment, may gain access to the fetus and potentially cause adverse effects in utero or postnatally [15-18]. Previous mouse exposure studies with Diesel exhaust during pregnancy supported a role of particulate air pollution upon adverse health effects in the central nervous system of the offspring [19-21]. Recently translocation of $50-250 \mathrm{~nm}$ polystyrene particles across human term placentas [22] was shown while no measurable translocation of 15 and $30 \mathrm{~nm}$ poly-ethylene-glycol coated AuNP was observed in a similar ex vivo model [23]. Indeed, a recent paper by Yamashita [24] reported size-dependent translocation from mouse placenta into fetuses following very high doses $(800 \mu \mathrm{g} /$ mouse $)$ of $\mathrm{SiO}_{2} \mathrm{NP}(70 \mathrm{~nm})$ and $\mathrm{TiO}_{2}$ NP (35 nm) administered by intravenous (IV) injection. Based on this study a commentary by Keelan [25] raised a number of questions such as "Whether size-dependent effects observed ... reflect size inherent exclusion property of the placenta itself or a characteristic of the specific nanomaterial investigated in the Yamashita study"; and "the mechanisms responsible which transported NP from within the trophoblast layers into the fetal circulation are still unclear". A just recently published paper reported on the translocation of IV injected $20 \mathrm{~nm}$ and $50 \mathrm{~nm}$ AuNP (stabilized in citrate and suspended in saline at a dose of $50 \mu \mathrm{g} /$ mouse) into the placenta of pregnant mice at gestation days 16 or 17 [26]. AuNP of both sizes were observed in maternal liver and the placenta but not in the fetal liver. Additional results of immunoreactivity tests suggested that
IV administration of AuNP may upregulate clathrin- and caveolin-mediated endocytosis at the maternal-fetal barrier in the mouse placenta.

Given the concerns about potential adverse health effects of NP and their demonstrated - albeit limited - propensity to cross cell barriers, we wanted to determine as to whether realistic, low doses of NP, once in the blood circulation, will cross placental barriers during pregnancy and accumulate in fetuses. The possible mechanisms and pathways to cross the placental barrier include simple diffusion or pinocytosis via clathrin, megalin or caveolin mediated transport $[27,28]$; and also via transtrophoblastic channels (canaliculi) of about 20-25 $\mathrm{nm}$ diameter that connect maternal blood across the hemochorial placenta of humans and rats directly to the fetal blood [29-31]. We hypothesize that these transtrophoblastic channels represent a pathway for NP in a size dependent manner from the placenta to fetal circulation in addition to endocytotic and diffusive transport mechanisms. In order not to overwhelm the body and its responses by irrelevantly high doses we used only small amounts of AuNP radioactively labelled with tracer amounts of ${ }^{198} \mathrm{Au}\left({ }^{198} \mathrm{AuNP}\right)$. We intravenously injected monodisperse, negatively charged, insoluble AuNP of three well-separated sizes: either well below $(1.4 \mathrm{~nm})$, or of similar size $(18 \mathrm{~nm})$ or well above $(80 \mathrm{~nm})$ the 20-25 nm size of the transtrophoblastic channels; all three AuNP were coated by ionic ligand molecules of sulfonated triphenylphosphine (S-TPP). Moreover, the selected AuNP sizes are good representatives for the entire NP range. In addition, $\mu$ g-range AuNP doses - although administered as a bolus - were chosen because there is sufficient evidence that toxic responses in the mother's body and in the fetuses are very unlikely at these rather low doses [32]. This prove-of-principle study was based on the determination of quantitative AuNP distribution in the entire organism of pregnant rats including placental and fetal tissues, see schematics in Figure 1.

\section{Animal model and hypothesis}

We used the pregnant rat model on day $18 \pm 1$ of gestation to assess in vivo the concept of ${ }^{198} \mathrm{AuNP}$ translocation across the placenta. The barrier between fetal and maternal part of the late stage placenta is only a few micrometer thick allowing for the exchange of nutritions and fluids $[31,34]$. The hemotrichorial anatomy of the rat placenta allows the maternal blood to be in direct contact with the chorion. The outer trophoblastic layer of the rat placenta is fenestrated so ${ }^{198}$ AuNP could enter into the labyrinth between the fenestrated outer layer and the middle trophoblastic layers of the placenta by diffusion (Figure 1). We hypothesize that in addition to diffusion also/or endocytotic processes may play a role in the transport of ${ }^{198}$ AuNP across the placental barrier [26]. These include pinocytotic or receptor mediated processes which are 


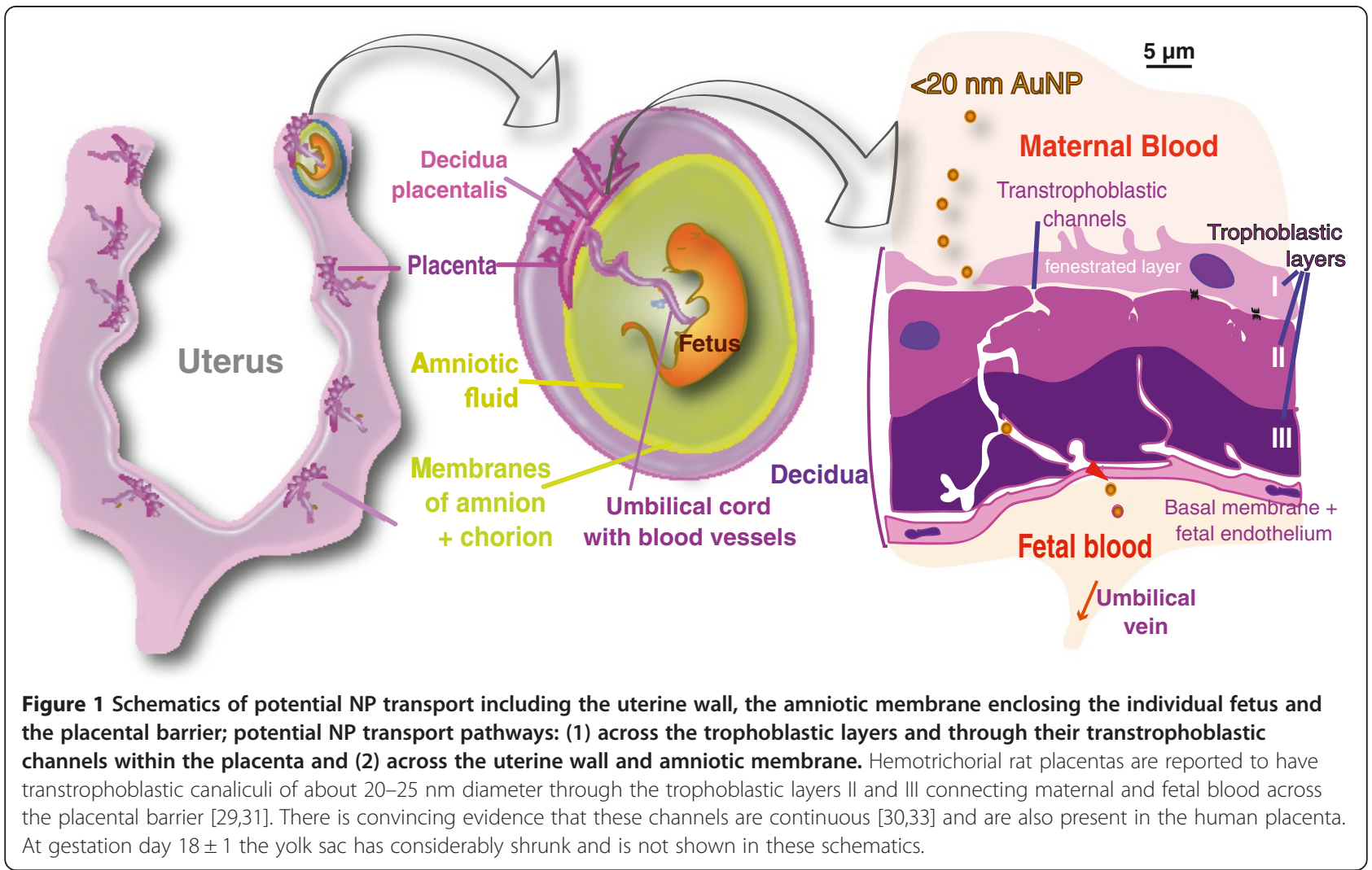

functional for nutrition and supply [31,34]. Yet, no experimental data on these transcellular pathways exist [35]. This pathway involves sequential transcellular passages through the trophoblastic cell layers of the labyrinth-type hemotrichorial rat placenta which is likely to increase the time of translocation and cellular retention of AuNP. Furthermore, hemotrichorial rat placentas have transtrophoblastic canaliculi of about 20-25 nm diameter through the trophoblastic layers II and III (Figure 1) connecting maternal and fetal blood across the placental barrier [29-31].

We suggest that $1.4 \mathrm{~nm}{ }^{198} \mathrm{AuNP}$ pass easily through these canaliculi while only a smaller fraction of $18 \mathrm{~nm}$ ${ }^{198}$ AuNP translocate via these canaliculi, in contrast to large $80 \mathrm{~nm}{ }^{198} \mathrm{AuNP}$ which will not be able to reach the fetal circulation by this pathway. Furthermore, based on the results obtained from the three different sized ${ }^{198} \mathrm{AuNP}$, we are able to estimate the contribution of transcellular translocation processes like endocytosis and exocytosis across the uterine and amniotic membranes as well as across the hemotrichorial trophoblastic layers.

\section{Role of the yolk sac}

While the yolk or vitelline sac provides most of the nutrition for the rat fetuses during the early gestational stage it does no longer play a significant supply function on day $18 \pm 1$ of gestation, even though it is still present but at a much smaller size. On day 18 the rat placenta functions are fully optimized to support the development of the growing fetuses in their individual amnions. No data exist for fetal translocation of NP via the vitelline sac; however, even if existent, it is most likely minimal when considering the small surface area of its membrane or the amniotic fluid.

\section{${ }^{198}$ AuNP dose considerations}

By using radioactive ${ }^{198} \mathrm{Au}$-labelling of the AuNP it was possible to detect anticipated tracer amounts in the placental and fetal samples of a few ng of ${ }^{198}$ AuNP following IV injection of low doses which should not result in a bolus overload effect. AuNP were neutron-activated prior to use only to the extent required to detect the ${ }^{198} \mathrm{AuNP}$ in the placental and fetal samples - see Methods. As a result the delivered radio-dose of about $100 \mathrm{kBq}$ of the short-lived ${ }^{198} \mathrm{Au}$ radio-isotope (half-life $2.7 \mathrm{~d}$ ) is far below from causing any acute radio-toxic effect during 24 hours retention time - even on a nanoscopic level in the direct vicinity of these ${ }^{198} \mathrm{AuNP}$ : the individual $1.4 \mathrm{~nm}$ and $18 \mathrm{~nm}{ }^{198} \mathrm{AuNP}$ contain maximally one ${ }^{198} \mathrm{Au}$ atom and the $80 \mathrm{~nm}{ }^{198} \mathrm{AuNP}$ contain on average $20{ }^{198} \mathrm{Au}$ atoms. Because the radio-isotope ${ }^{198} \mathrm{Au}$ is chemically the same as in the AuNP core there is no leaching of the radio-label out of the insoluble matrix of AuNP. Yet, the selection of such rigid experimental parameters has some limitations regarding the visualisation within the tissues: 
For the tiny $1.4 \mathrm{~nm}$ AuNP clusters consisting of $55 \mathrm{Au}$ atoms in stable configuration there is currently no imaging technology for biological tissues to identify them. (Imaging requires carefully cleaned and specially prepared substrate surfaces.) Even silver enhancement does not work for AuNP $<2$ nm [36].

Likewise, the anticipated low amount of tracer results in such a low number of the largest $80 \mathrm{~nm}$ AuNP to be expected in the placenta that they are practically not detectable by electron microscopy. For example, in order to detect 30 AuNP of $80 \mathrm{~nm}$ size an estimated number of $2 \times$ $10^{4}$ pieces of $3 \times 3 \mathrm{~mm}^{2} \times 80 \mathrm{~nm}$ fetal tissue slices would be required for detection by electron microscopy screening which is unfeasible with current technology.

\section{Results and discussion}

Physico-chemical properties of monodisperse, negatively charged, insoluble and radio-labeled ${ }^{198} \mathrm{AuNP}$ are given in the Methods section and have been described previously $[5,6,10,11]$. In addition, we provide in vivo data in the Supporting Information suggesting rapid replacement of the ionic sulfonated triphenylphosphene (S-TPP) surface modification from the AuNP after IV injection.

\section{Extra-uterine ${ }^{198}$ AuNP biodistribution}

As shown previously in non-pregnant female rats we found prominent ${ }^{198}$ AuNP uptake and retention in the liver $24 \mathrm{~h}$ after IV injection of ${ }^{198} \mathrm{Au}$ labelled AuNP $[6,10]$. The retained fraction of IV administered $18 \mathrm{~nm}$ or $80 \mathrm{~nm}{ }^{198} \mathrm{AuNP}$ in mononuclear phagocyte system (MPS) (here represented by liver, spleen and lungs) was greater than 0.97 in pregnant and non-pregnant rats (Figure 2); note fractions are ${ }^{198} \mathrm{Au}$ radioactivity and, hence, mass based. These fractions were dominated by AuNP retention in the liver. Retention in all other organs and tissues did not differ significantly between pregnant and non-pregnant rats for both, $18 \mathrm{~nm}$ and $80 \mathrm{~nm}{ }^{198} \mathrm{AuNP}$. In contrast, we found a fraction of $0.52 \pm 0.04$ of the administered $1.4 \mathrm{~nm}{ }^{198} \mathrm{AuNP}$ in the MPS of non-pregnant rats and a significantly higher fraction of $0.71 \pm 0.02$ in the MPS of pregnant rats, respectively. Both fractions were dominated by AuNP retention in the liver $(0.50 \pm 0.03$ and $0.68 \pm 0.02$, respectively). Interestingly, lower lung retention and higher liver retention were significantly different $(p<0.0001)$ for pregnant rats when compared to non-pregnant rats, but there was no difference in spleen retention. A more detailed discussion is given in Additional file 1. Additionally, $1.4 \mathrm{~nm}$ ${ }^{198}$ AuNP retention in kidneys, heart and skin and remaining carcass of pregnant rats were significantly $(\mathrm{p}<0.0001)$ lower. Carcass consisted of skeleton and soft tissues (muscles and fat); yet, a sample of muscle and humerus did not significantly vary between pregnant and non-pregnant rats.
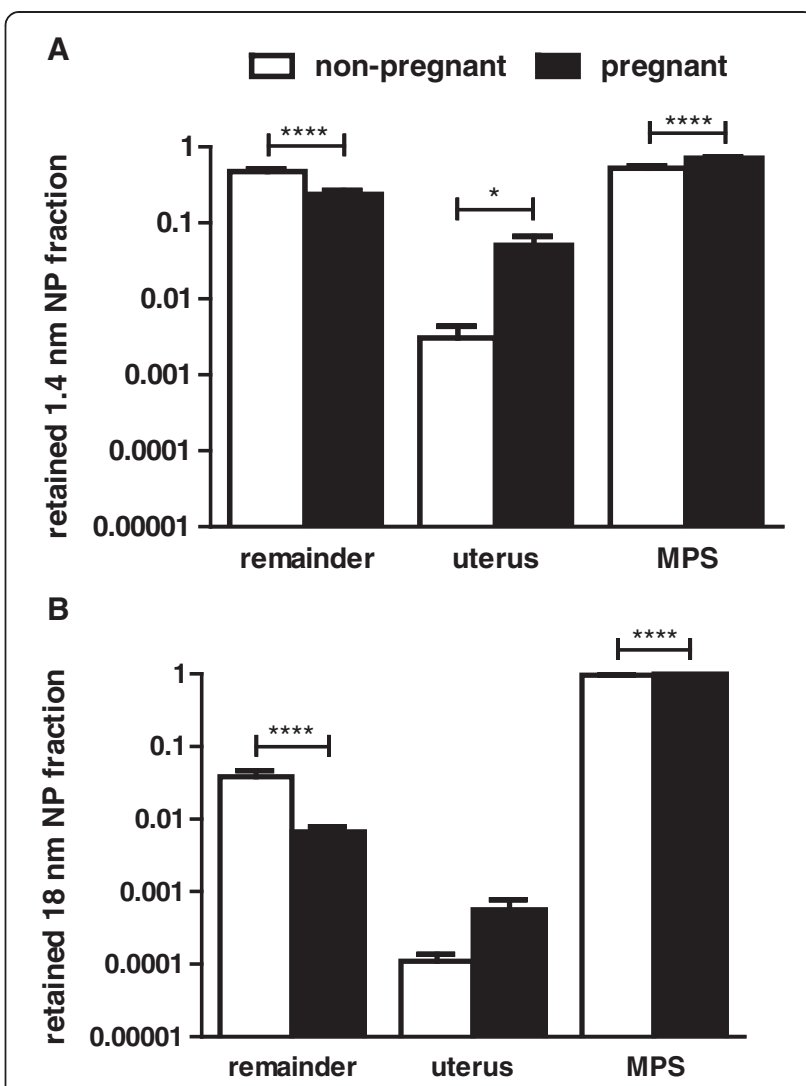

C

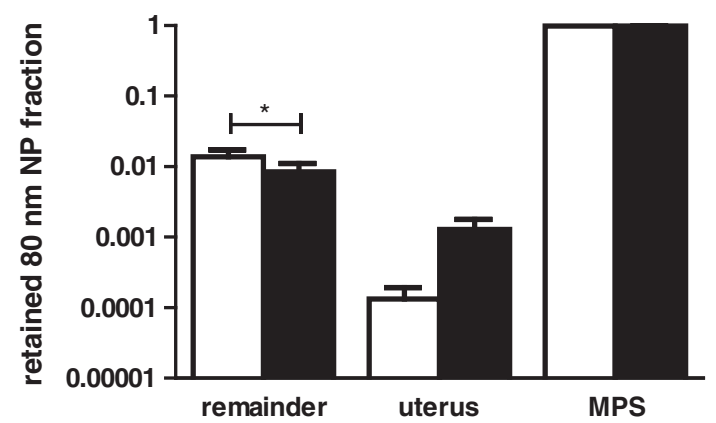

Figure 2 Comparison of pregnant versus non-pregnant rats: comparison of 24-hour retained ${ }^{198}$ AuNP fractions relative to the initially administered dose in either pregnant rats in their $3^{\text {rd }}$ trimester or non-pregnant controls: upper panel $1.4 \mathrm{~nm}$ AuNP; middle panel $18 \mathrm{~nm}$ AuNP; lower panel $80 \mathrm{~nm}$ AuNP. Note that fractions are ${ }^{198} \mathrm{Au}$ radioactivity- and, hence, Au-mass based. Compartments are the (A) mononuclear phagocytic system (MPS consisting of liver, spleen, lungs), (B) the remaining carcass (remainder) including skeleton, soft tissues, skin and all other organs and $(\mathbf{C})$ the uterus with or without the progeny. MPS and remainder samples were corrected for ${ }^{198}$ AuNP in the remaining blood. Note the uterus of the pregnant rats comprises of the uterine walls, the placentas and all amnions with fetuses. Data are given as fractions of the intravenously injected ${ }^{198}$ AuNP doses. $\left(n=4\right.$; ${ }^{*} p<0.05$; ** $p<0.01$; $\left.{ }^{* * *} p<0.001{ }^{* * * *} p<=0.0001\right)$. Statistical analysis by one-way analysis of variance (ANOVA) followed by post hoc Sidak's multiple comparisons test. 
Retention of the administered $1.4 \mathrm{~nm}, 18 \mathrm{~nm}$ and $80 \mathrm{~nm}{ }^{198} \mathrm{AuNP}$ was significantly lower in the remainder of pregnant rats compared to non-pregnant rats. As detailed in Additional file 1 urinary excretion of $18 \mathrm{~nm}$ and $80 \mathrm{~nm}{ }^{198} \mathrm{AuNP}$ was negligible in non-pregnant rats; but about half of the of $0.05-0.1$ excreted fraction of $1.4 \mathrm{~nm}{ }^{198} \mathrm{AuNP}$ were found in urine in both pregnant and non-pregnant rats indicating renal filtration of a few percent of the injected $1.4 \mathrm{~nm}{ }^{198} \mathrm{AuNP}$. Fecal excretion in both pregnant and non-pregnant rats resulted from hepato-biliary AuNP clearance [6] and shows strong inverse size dependency, Additional file 1: Figure S4. For all three ${ }^{198}$ AuNP, the hepato-biliary AuNP clearance was significantly reduced in pregnant rats compared to non-pregnant controls, which is discussed in more detail in the Additional file 1. These differences indicate that the altered physiology of the pregnant rat significantly affects AuNP biokinetic, a finding that requires followup studies to identify underlying mechanisms.

\section{Intra-uterine ${ }^{198}$ AuNP biodistribution in pregnant rats}

Twenty-four hours after a single IV injection we found a significantly higher ${ }^{198}$ AuNP fraction in the about 10 fold larger uterus of pregnant rats including the total progeny compared to the rather small uterus of the nonpregnant rats (Figure 2). However, when normalizing the ${ }^{198}$ AuNP content per weight of uterus or blood, the concentrations for a given ${ }^{198} \mathrm{AuNP}$ size were similar between pregnant and non-pregnant rats. Yet, there were consistent differences for different ${ }^{198}$ AuNP sizes, Additional file 1: Figure S2; i.e. ${ }^{198}$ AuNP concentrations in the uterus are mainly determined by the ${ }^{198} \mathrm{AuNP}$ concentration in the uterine blood.

The translocated ${ }^{198}$ AuNP fractions in the total uterus were $5 \%$ of the IV injected $1.4 \mathrm{~nm}{ }^{198} \mathrm{AuNP}$ and about $0.1 \%$ of both $18 \mathrm{~nm}$ and $80 \mathrm{~nm}{ }^{198}$ AuNP, respectively, Figure 2. This resulted in detectable AuNP-mass-based fetal fractions of 0.0006 and 0.00005 of $1.4 \mathrm{~nm}$ and $18 \mathrm{~nm}{ }^{198} \mathrm{AuNP}$, respectively, but no $80 \mathrm{~nm}$ fraction in fetuses indicating the importance of the AuNP size, Figure 3.

Figure 3 shows retained ${ }^{198} \mathrm{AuNP}$ fractions (of the injected ${ }^{198} \mathrm{AuNP}$ ) in the four compartments of the pregnant uterus ((a) uterine wall, (b) placentas + umbilical cords + amniotic membranes, (c) total amniotic fluid and (d) all fetuses) $24 \mathrm{~h}$ after IV injection of $1.4 \mathrm{~nm}, 18 \mathrm{~nm}$ and $80 \mathrm{~nm}{ }^{198}$ AuNP. Results of the statistical analysis are shown in Table 1. Nearly two orders of magnitude higher fractions of $1.4 \mathrm{~nm}{ }^{198} \mathrm{AuNP}$ were found in the uterine wall or the placentas (compartment b) than for $18 \mathrm{~nm}$ or $80 \mathrm{~nm}$ ${ }^{198} \mathrm{AuNP}$. In amniotic fluid we found detectable ${ }^{198} \mathrm{AuNP}$ fractions of all three sizes. The $1.4 \mathrm{~nm}{ }^{198} \mathrm{AuNP}$ fraction of 0.005 was 100-200-fold higher than those detected for the larger ${ }^{198}$ AuNP. There was no significant difference in the amniotic fluid fractions of retained $18 \mathrm{~nm}$ and $80 \mathrm{~nm}$

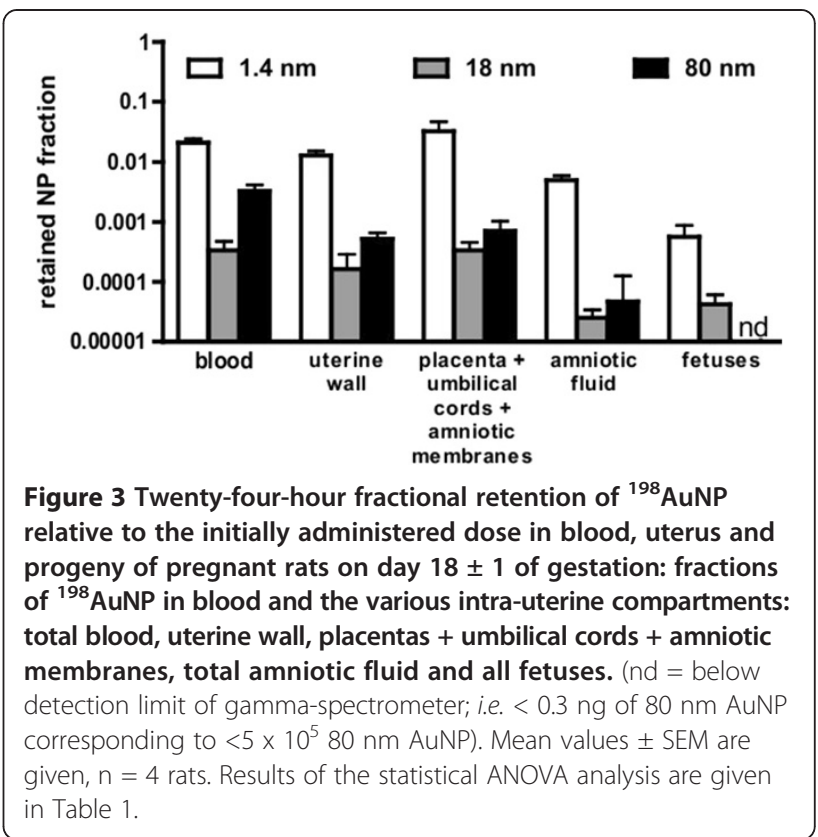

${ }^{198}$ AuNP. Interestingly, $1.4 \mathrm{~nm}{ }^{198} \mathrm{AuNP}$ concentrations per weight of blood, uterine walls and placenta were significantly (one order of magnitude) higher than those of the larger ${ }^{198}$ AuNP; Additional file 1: Figure S3.

\section{${ }^{198}$ AuNP translocation through the placenta towards the fetus}

Figure 3 shows small but detectable amounts of $1.4 \mathrm{~nm}$ and $18 \mathrm{~nm}{ }^{198} \mathrm{AuNP}$ in the fetuses of pregnant rats but none in fetuses treated with $80 \mathrm{~nm}{ }^{198} \mathrm{AuNP}$. Only fractions of $0.0006(30 \mathrm{ng})$ and $0.00004(0.1 \mathrm{ng})$ of $1.4 \mathrm{~nm}$ and $18 \mathrm{~nm}$ AuNP, respectivel, were detected in the fetuses. Hence, the absence of $80 \mathrm{~nm}{ }^{198} \mathrm{AuNP}$ demonstrates that even tracer amounts of ${ }^{198} \mathrm{AuNP}$ were not translocated by any mechanism consistent with our hypothesis that $80 \mathrm{~nm}{ }^{198} \mathrm{AuNP}$ are too large to pass transtrophoblastic channels. Our finding that the $80 \mathrm{~nm}$

Table 1 Statistical ANOVA analysis for Figure 3

\begin{tabular}{llll}
\hline ANOVA analysis & AuNP size & AuNP size & AuNP size \\
\hline Compartm./fluid & 1.4 vs. 18 & 1.4 vs. 80 & 18 vs. 80 \\
\hline Blood & $* * * *$ & $* * * *$ & $\mathrm{~ns}$ \\
\hline Uterine wall & $* * * *$ & $* * * *$ & $\mathrm{~ns}$ \\
\hline $\begin{array}{l}\text { Placenta + umbilical } \\
\text { cords + amniotic } \\
\text { membranes }\end{array}$ & $* * *$ & $* *$ & $\mathrm{~ns}$ \\
\hline Amniotic fluid & & & \\
\hline Fetuses & $* * * *$ & $* * * *$ & $\mathrm{~ns}$ \\
\hline
\end{tabular}

Results of statistical analysis by one-way analysis of variance (ANOVA) followed by post hoc Tukey's multiple comparisons test are given. ( $\mathrm{ns}=$ not significant; $\left.{ }^{*} \mathrm{p}<0.05 ;{ }^{* *} \mathrm{p}<0.01 ;{ }^{* * *} \mathrm{p}<0.001 ;{ }^{* * * *} \mathrm{p}<=0.0001\right)$. Note that fractions are ${ }^{198} \mathrm{Au}$ radioactivity- and, hence, Au-mass based. 
${ }^{198}$ AuNP could not be observed in the fetus contrasts with those of Yamashita and co-workers [24] who found that $800 \mu \mathrm{g}$ i.v. injected $70 \mathrm{~nm} \mathrm{SiO}_{2} \mathrm{NP}$ or $35 \mathrm{~nm} \mathrm{TiO}_{2}$ NP not only crossed into fetal tissue but also induced significant fetal toxicity. This difference is unlikely due to NP size (70 nm vs. $80 \mathrm{~nm}$ ) but could be due to either material differences $\left(\mathrm{Au} v s . \mathrm{SiO}_{2}\right.$ or $\mathrm{TiO}_{2}$ ) or - which we think might be a significant confounder - the nonphysiologically high bolus type $(800 \mu \mathrm{g} /$ mouse IV of $\mathrm{SiO}_{2}$ or $\mathrm{TiO}_{2} \mathrm{NP}$ ) delivery which may open normally not functional translocation pathways as it is well known from lung particle overload studies [37]. Regarding the 10 -fold difference in weight of rats and mice their NP doses exceeded ours by about a factor of 1000 . In contrast, the above mentioned, very recent study by Rattanpinyopituk and coworkers on the translocation of IV injected $20 \mathrm{~nm}$ and $50 \mathrm{~nm}$ AuNP into the placenta of mice reported only the presence of AuNP in the placenta but not in the fetuses [26]. AuNP sizes are rather similar to our $18 \mathrm{~nm}$ and $80 \mathrm{~nm}$ AuNP and the administered dose was only 10-fold higher than ours. The absence of AuNP in the fetuses may be related to the lower sensitivity of the chemical Au analysis used (ICP-MS) but may also be affected by possible coagulation of the citrate-stabilized AuNP in saline leading to larger agglomerates which could not cross the placental barrier although immunoreactivity tests suggested that clathrin- and caveolin-mediated endocytosis was upregulated at the maternal-fetal barrier.

Since we did not find $80 \mathrm{~nm}{ }^{198} \mathrm{AuNP}$ in fetuses we can conclude: transport of all three AuNP sizes across the placenta by macropinocytosis can be ruled out because all three sizes of ${ }^{198} \mathrm{AuNP}$ would likely be taken up in the several-hundred-nm large pinocytotic vesicles independent of the AuNP sizes we used [38]. But we also have to take into account the transport across the placental barrier by receptor-mediated endocytotic processes as the recent study of Rattanapinyopituk and co-workers suggests [26]. Each of our ${ }^{198} \mathrm{AuNP}$ will lose the S-TPP coating immediately after IV injection [39] and likely form particleprotein-conjugates with serum proteins shown by results of in vitro studies [40-42] and as suggested by our preliminary in vivo data - see Additional file 1. Formation of particle-protein-conjugates depends on particle size, material and surface properties as well as protein concentrations and their composition in serum [40]. Although the results of the cited reports are based on in vitro studies, the formation of a protein corona very likely differs between the three Au NP sizes used as we recently showed by our in vitro protein binding studies using the same AuNP [43]. As a consequence, mechanisms of cell uptake and translocation of the three AuNP across the various hemochorial cell layers can be quite different because receptor mediated endocytosis of particles depends both on particle size and the adsorbed proteins. Indeed, our data are consistent with the notion that $80 \mathrm{~nm}{ }^{198}$ AuNP-proteinconjugates are too big for endocytotic transport across the various cell types of the trophoblastic layers into the fetal blood (Figure 1); therefore, no $80 \mathrm{~nm}$ AuNP were found in the fetuses. On the other hand we cannot exclude that a fraction of the $18 \mathrm{~nm}{ }^{198} \mathrm{AuNP}$ found in the fetus was transported via endocytosis across the cells of the trophoblastic layers [26], depending on the size and composition of the conjugated protein-layer around the AuNP. For the smallest $1.4 \mathrm{~nm}{ }^{198} \mathrm{AuNP}$ together with their proteinconjugate endocytotic transport across the trophoblastic layers is most likely, while the passage of the $1.4 \mathrm{~nm}$ AuNP through trophoplastic channels is likely to act as an additional and competitive transport across the trophoblastic layers of the placenta.

Because transcellular ${ }^{198}$ AuNP transport from the maternal to the fetal side involves the transport across multiple cell layers of the trophoblast, it likely takes considerably longer compared to a faster passage through a single cell layer and it is also likely to be slower than their passage through transtrophoblastic canaliculi. We base this suggestion on estimates given in the Additional file 1 where we used our earlier in vivo translocation data of the same sized ${ }^{198}$ AuNP across the alveolo-capillary-barrier - a membrane consisting of a single cell epithelium, the basal membrane and a single cell endothelium. - Using this comparison, we estimate that the contribution of transcellular 24-h translocation across the trophoblastic layers is a minor fraction of the observed $1.4 \mathrm{~nm}$ and $18 \mathrm{~nm}$ AuNP in fetuses; see Additional file 1.

\section{${ }^{198}$ AuNP translocation through the amniotic membrane towards the fetus}

Production of amniotic fluid in late stage pregnancy is mainly arranged by an inflow of fetal urine and liquid secretion from fetal lungs as well as trans-membranous diffusion across the amniotic membranes, while the main outflow is regulated by fetal swallowing and intra-membranous absorption [34,44-46]. Transdermal uptake by rat fetuses appears to be unlikely in the third trimester of gestation as the skin is already keratinized [31]. The amniotic membranes consist of an epithelial cell layer on a basal membrane and provide a large surface. Hence, ${ }^{198}$ AuNP can reach the amniotic fluids only across these membranes, see Figure 1.

Figure 3 shows the significant, two orders of magnitude higher $1.4 \mathrm{~nm}{ }^{198} \mathrm{AuNP}$ fraction in the amniotic fluid compared to the amniotic fluid fractions of $18 \mathrm{~nm}$ and $80 \mathrm{~nm}$ ${ }^{198}$ AuNP. This may be explained by differences in the diffusion of $1.4 \mathrm{~nm}{ }^{198} \mathrm{AuNP}$ versus the larger ${ }^{198} \mathrm{AuNP}$. The $18 \mathrm{~nm}$ and $80 \mathrm{~nm}{ }^{198} \mathrm{AuNP}$ amniotic fractions are not significantly different from each other indicating that their translocation to the amniotic fluid is not due to diffusional transport. Instead, this implies transcellular transport 
which is believed to be independent of size for $18 \mathrm{~nm}$ and $80 \mathrm{~nm}{ }^{198} \mathrm{AuNP}$ [38]. While the ${ }^{198}$ AuNP concentration per unit mass of blood and amniotic fluid was rather similar for $1.4 \mathrm{~nm}{ }^{198} \mathrm{AuNP}$, it was one order of magnitude less for both $18 \mathrm{~nm}$ and $80 \mathrm{~nm}{ }^{198} \mathrm{AuNP}$ in the amniotic fluid than that in blood - see Additional file 1: Figure S3. This difference suggests that diffusion is the predominant transport of the $1.4 \mathrm{~nm}{ }^{198} \mathrm{AuNP}$ across the amniotic membrane. As stated above, the similarity of $18 \mathrm{~nm}$ and $80 \mathrm{~nm}$ ${ }^{198}$ AuNP concentrations in the amniotic fluid are consistent with size-independent transcellular transport across the amniotic membrane.

The finding of detectable fractions of all three ${ }^{198}$ AuNP in the amniotic fluid may point to another potential pathway of ${ }^{198} \mathrm{AuNP}$ uptake into the fetuses involving swallowing of the amniotic fluid. During normal pregnancy, there is no fecal excretion by the fetus, so the ${ }^{198} \mathrm{AuNP}$ are expected to be stored in the fetal gastro-intestinal-tract. Since the fractions of $18 \mathrm{~nm}$ and $80 \mathrm{~nm}{ }^{198} \mathrm{AuNP}$ in the amniotic fluid were similar and fetal swallowing is AuNP size independent one should expect that - if swallowing is the underlying cause for the finding of AuNP in the fetus the fractions of $18 \mathrm{~nm}$ and $80 \mathrm{~nm}{ }^{198} \mathrm{AuNP}$ in the fetus should be similar and reflecting their concentrations in the amniotic fluid. However, we did not find $80 \mathrm{~nm}$ AuNP in the fetuses in contrast to $18 \mathrm{~nm}$ AuNP, so we conclude that swallowing of $18 \mathrm{~nm}$ or $80 \mathrm{~nm}{ }^{198} \mathrm{AuNP}$ by the fetuses can be excluded unless the amount being swallowed is below our limit of detection. Consequently, the observed $18 \mathrm{~nm}$ ${ }^{198} \mathrm{AuNP}$ content in the fetuses results from transfer through the placenta, most likely via transtrophoblastic canaliculi although receptor-mediated endocytotic processes described above cannot fully be excluded.
The translocation mechanisms may not necessarily be the same for the $1.4 \mathrm{~nm}{ }^{198} \mathrm{AuNP}$ found in the fetuses because the amount of $1.4 \mathrm{~nm}{ }^{198} \mathrm{AuNP}$ in the amniotic fluid is two orders of magnitude higher than those of $18 \mathrm{~nm}$ and $80 \mathrm{~nm}{ }^{198} \mathrm{AuNP}$; so fetal swallowing may still play a role for these small $1.4 \mathrm{~nm}$ AuNP. However, given that the ratio between amounts in the fetal and the placental ${ }^{198} \mathrm{AuNP}$ (see Figure 3) are approximately the same for the $18 \mathrm{~nm}$ and $1.4 \mathrm{~nm}{ }^{198} \mathrm{AuNP}$ and given - as explained above - that none of the fetal $18 \mathrm{~nm}{ }^{198} \mathrm{AuNP}$ is due to swallowing, this implies that only a minimal, if any, amount of the fetal $1.4 \mathrm{~nm}{ }^{198} \mathrm{AuNP}$ is a result of swallowing.

\section{Relevance of the AuNP doses administered to the mother and acuumulated by the fetuses}

As mentioned above using the technology of radioactive ${ }^{198} \mathrm{Au}$-labelling of the AuNP it was possible to detect anticipated tracer amounts in the placental and fetal samples of a few ng of ${ }^{198} \mathrm{AuNP}$ following IV injection of low mass dose of 5,3 and $27 \mu \mathrm{g} /$ rat of $1.4 \mathrm{~nm}, 18 \mathrm{~nm}$ and $80 \mathrm{~nm}$ AuNP, respectively, Table 2. These doses resulted in fetal AuNP mass accumulations of $30 \mathrm{ng}$ and $0.1 \mathrm{ng}$ fractions of $1.4 \mathrm{~nm}$ and $18 \mathrm{~nm}$ AuNP but none of the $80 \mathrm{~nm}$ AuNP. In order to estimate whether the IV administered AuNP doses are relevant to those delivered to the lungs which translocated from the lungs into circulation we compare the data obtained after intratracheal instillation of the same set of AuNP, published previously [43]. There we instilled rather similar AuNP doses intratracheally which are given in Table 3 . In addition, the fraction and mass of the translocated AuNP across the air-blood-barrier $(\mathrm{ABB})$ are given. When comparing the AuNP concentrations in blood the doses administered to the pregnant rats

Table 2 Parameters and dose metrics of administered ${ }^{198}$ AuNP; additionally ${ }^{198}$ AuNP doses in the fetuses 24 hours after intravenous injection

\begin{tabular}{|c|c|c|c|}
\hline AuNPs, core diameter (nm) & 1.4 & 18 & 80 \\
\hline Hydrodynamic diameter $(\mathrm{nm})$ after neutron irradiation & $2.9^{\#}$ & $21^{\$}$ & $94^{\$}$ \\
\hline$\left(\mathrm{Ph}_{2} \mathrm{PC}_{6} \mathrm{H}_{4} \mathrm{SO}_{3} \mathrm{Na}\right) ;$ ligand molecules/NP & 12 & $1.5-2 \times 10^{3+}$ & $3-4 \times 10^{4+}$ \\
\hline Specific ${ }^{198} \mathrm{Au}$ radioactivity $(\mathrm{GBq} / \mathrm{g})$ & 19 & 31 & 8.3 \\
\hline Isotope ratio of ${ }^{198} \mathrm{Au}$ to stable ${ }^{197} \mathrm{Au}$ & $410^{-8}$ & $610^{-8}$ & $1.210^{-6}$ \\
\hline Ratio of ${ }^{198} \mathrm{Au}$ per AuNP & $210^{-6}$ & $110^{-2}$ & 19 \\
\hline pH Value of suspension & 5.6 & 6.4 & 5.4 \\
\hline Zeta potential (mV) & $-20.0 \pm 2.4$ & $-22.8 \pm 3.1$ & $-27.1 \pm 1.3$ \\
\hline Administered mass of AuNP $(\mu \mathrm{g})$ per rat & $5.2 \pm 0.6$ & $3.2 \pm 0.9$ & $26.5 \pm 5.0$ \\
\hline Administered number of AuNP per rat & $1.9 \pm 0.2 \times 10^{14}$ & $5.5 \pm 1.5 \times 10^{10}$ & $5.2 \pm 1.0 \times 10^{9}$ \\
\hline AuNP mass (ng) retained in fetuses & 30 & 0.12 & $<0.1^{*}$ \\
\hline Number of AuNP retained in fetuses & $1.2 \times 10^{11}$ & $2.4 \times 10^{6}$ & $<2 \times 10^{4 *}$ \\
\hline
\end{tabular}

${ }^{+}$Estimated as a result of a double layer of phosphine molecules observed in TEM [47].

"As determined earlier [48].

${ }^{\$}$ DLS measurement using Malvern HPPS5001, Herrenberg, Germany.

*Below detection limit. 
Table 3 Comparison of intratracheally instilled AuNP dose and the resulting translocated fraction into blood circulation with intravenously injected AuNP doses

\begin{tabular}{llll}
\hline AuNP core diameter $(\mathrm{nm})$ & 1.4 & 18 & 80 \\
\hline IT AuNP dose $(\mu \mathrm{g})$ & 2.6 & 1.6 & 17.6 \\
\hline Transloc Fraction & 0.08 & 0.002 & 0.001 \\
\hline Translocated AuNP mass $(\mu \mathrm{g})$ & 0.208 & 0.003 & 0.018 \\
\hline IV AuNP dose pregnant rats $(\mu \mathrm{g})$ & 5.2 & 3.2 & 26.5 \\
\hline Dose factor & 25 & 1000 & 1506 \\
\hline
\end{tabular}

they are 25, 1000 and 1500 times higher for $1.4 \mathrm{~nm}, 18 \mathrm{~nm}$ and $80 \mathrm{~nm}$ AuNP, respectively, than those of the AuNP which had crossed the ABB. However, also in the previous paper we had aimed to minimize the delivered doses to the lungs of the rats.

Furthermore, we have performed an inhalation study of freshly generated $20 \mathrm{~nm}$ AuNP using the same branch of adult, female rats. This AuNP aerosol was optimized for the highest possible number concentration of about $10^{7} \mathrm{AuNP} / \mathrm{cm}^{3}$ being stable for the 5 -seconds time between aerosol generation by spark ignition technology and inhalation [49]. This exposure led to an aerosol mass concentration of $1.2 \mathrm{mg} / \mathrm{m}^{3}$ due to the high $\mathrm{Au}$ density. Using the minute ventilation volume of adult rats of $0.25 \mathrm{~L} / \mathrm{min}$ [50] and a presumed deposition fraction 0.4 of the inhaled aerosol, then two hours of inhalation are required to deposit about $15 \mu \mathrm{g}$ in the rat's lungs. This is ten-fold of the intratracheally instilled dose but the AuNP dose which had crossed the ABB would still be two orders of magnitude lower than what had been IV injected to the pregnant rats. For the other two AuNP we don't have any aerosol data available but similar relations are expected. However, when screening the current literature on nanomedicinal treatments using AuNP the intravenously injected doses used in experimental animals (mostly mice) are much higher in the range of $1-10 \mathrm{mg} / \mathrm{kg}$ body weight [51-55]. In addition, there are a number of preclinical human applications for cancer diagnistics and treatment in which doses of 1-5 mg/ $\mathrm{kg} \mathrm{BW}$ of superparamagnetic iron oxide NP or have been used. These preclinical studies have been reviewed [56,57]. Regarding these NP doses in nanomedicinal applications, our AuNP IV doses of $20-100 \mu \mathrm{g} / \mathrm{kg}$ BW are very low.

\section{Extrapolation of AuNP translocation from rat to human placenta}

McArdle and coworkers [58] suggest that the transport mechanisms across the placental barrier are similar in species with hemochorial placentas such as rats and humans. Both species have transtrophoblastic channels of about 20-25 nm diameter [29-31] and additional transcellular endocytotic transport mechanisms should be similar. The labyrinth type placenta of rats with a thicker barrier of three trophoblastic layers, i.e. more cellular layers than in the human placenta with only one trophoblastic layer, appears to be a conservative model for AuNP transport towards the human fetus. Therefore, we suggest that a similar perhaps even higher AuNP translocation into the human fetus may occur after IV injection.

Indeed, ex vivo studies using the human term placenta showed a small but significant translocation of bigger polystyrene particles (from $50 \mathrm{~nm}$ up to $240 \mathrm{~nm}$ ) [22]. Still the highest translocation was found for the smallest NP supporting the importance of NP size but may indicate also some additional processes which may enable NP to cross the human placental barrier in small amounts. Note that the human term placenta after birth is not equivalent to 18-day rat placenta and may already have a compromised barrier function.

Recently, Saunders [35] concluded that currently there is very limited data on the translocation of NP towards the human fetus. Fuchs and co-workers [14] also speculate that endocytotic and transcytotic processes with diffusion, carrier-mediated and vesicular transport are the main mechanisms which transports nutrients like glucose, amino acids, lipids, water, ions, vitamins, minerals and oxygen through the placental barrier. But they also report, that the pathways are poorly or not at all characterized. In addition, the recent study on $20 \mathrm{~nm}$ and $50 \mathrm{~nm}$ AuNP failed to demonstrate translocation across the placental barrier into the fetuses based on the ICP-MS method used [26].

Similarly, we cannot extrapolate these fractional accumulations in the fetus to other NP contained in consumer products or medication like titania, silica, ceria, silver or carbonaceous NP. Furthermore, any extrapolation to the differential behavior of conventional drugs in pregnant versus non-pregnant rats appears not to be valid since molecules of conventional drugs behave completely different in the organism compared to NP. Yet, the size dependency for translocation may well applicable to other NP materials. So, while these results suggest that the fetus is well protected against larger NP the unborne may well be exposed to very small NP during the mother's pregnancy through medical treatment or via food consumption.

\section{Conclusions}

In conclusion, our study design and results allowed to differentiate between two potential ${ }^{198} \mathrm{AuNP}$ pathways from maternal blood to the fetus in a pregnant rat model at gestation day 18 - (1) via placenta by transtrophoblastic channels competing with transcellular endocytotic passage across multiple cell layers and (2) via transport across the amniotic membrane - both pathways are ${ }^{198} \mathrm{AuNP}$ size dependent:

- The absence of $80 \mathrm{~nm}{ }^{198}$ AuNP in the fetuses is consistent with our hypothesis that these AuNP are 
too large to pass the $\sim 20-25 \mathrm{~nm}$ sized transtrophoblastic channels.

- We infer from our results that both $1.4 \mathrm{~nm}$ and $18 \mathrm{~nm}{ }^{198}$ AuNP are transported through the placenta - via transtrophoblastic channels and/or transcellular receptor-mediated endocytotic mechanisms. (Note that this study did not allow a clear distinction between these two transport pathways)

- All three ${ }^{198}$ AuNP sizes cross the amniotic membrane: the $1.4 \mathrm{~nm}{ }^{198}$ AuNP by diffusion and/or transcellular transport but the $18 \mathrm{~nm}$ and $80 \mathrm{~nm}$ ${ }^{198}$ AuNP mainly by the latter transport and are detectable in the amniotic fluid but they are not incorporated into the fetuses within 24 hours.

Therefore, our overall conclusion is that translocation through transtrophoblastic channels is the dominating pathway for ${ }^{198} \mathrm{AuNP}$ smaller than the channel diameter of about 20-25 $\mathrm{nm}$. Furthermore, we suggest that these results can be extrapolated to humans because of the similarity between human and rat late-term placenta.

\section{Methods}

Sulfonated triphenylphosphine (S-TPP) coated AuNP of $1.4 \mathrm{~nm}, 18 \mathrm{~nm}$ and $80 \mathrm{~nm}$ core diameter were synthesized following known procedures [59,60]. While $1.4 \mathrm{~nm}$ AuNP were ideally monodisperse, the standard deviation of both $18 \mathrm{~nm}$ and $80 \mathrm{~nm}$ AuNP was about 10\% in the distilled water suspension, see Table 2. All AuNP were radio-labeled with ${ }^{198} \mathrm{Au}$ by neutron activation at a neutron flux of $10^{14} \mathrm{~cm}^{-2} \mathrm{sec}^{-1}$ in the research reactor of Helmholtz Center Berlin, Germany $\left({ }^{198} \mathrm{Au}\right.$ half-life $2.69 \mathrm{~d}$; $411 \mathrm{keV}$ gamma emission used for gammaspectroscopic analysis). Gold amounts and irradiation times were adjusted to provide sufficient ${ }^{198} \mathrm{Au}$ radioactivity for the subsequent in vivo studies. Specific ${ }^{198} \mathrm{Au}$ radioactivity and the isotope ratio of ${ }^{198} \mathrm{Au}$ to stable ${ }^{197} \mathrm{Au}$ are given in Table 2. Note that this ratio is very low such that statistically only one ${ }^{198} \mathrm{Au}$ isotope can be found in a $1.4 \mathrm{~nm}$ and $18 \mathrm{~nm}$ AuNP and most of the $1.4 \mathrm{~nm}$ AuNP do not contain any ${ }^{198} \mathrm{Au}$ atom at all while there are fewer $18 \mathrm{~nm}$ AuNP containing no ${ }^{198} \mathrm{Au}$ isotope; but in the $80 \mathrm{~nm}$ AuNP an average number of $20{ }^{198} \mathrm{Au}$ atoms are contained in the AuNP matrix, Table 2 .

After neutron irradiation immediately prior to rat application the $1.4 \mathrm{~nm}{ }^{198} \mathrm{AuNP}$ solution was filtered through a $10 \mathrm{~cm}$ column of Celite to remove agglomerates; losses determined by ${ }^{198} \mathrm{Au}$ radioactivity accounted for about $10 \%$ [10]. The $18 \mathrm{~nm}$ and $80 \mathrm{~nm}{ }^{198} \mathrm{AuNP}$ suspensions were visually controlled for precipitates and their correct pink translucent color of the colloidal suspension immediately prior to the application in rats; no change in color or precipitation and no changes were found compared to the suspension prior to irradiation. In case of $18 \mathrm{~nm}$ and $80 \mathrm{~nm}{ }^{198}$ AuNP their UV absorption peak at $523 \mathrm{~nm}$ was unchanged prior to and three weeks after irradiation (data not shown). The hydrodynamic diameters (HD) of the $18 \mathrm{~nm}$ and $80 \mathrm{~nm}$ AuNP were measured in duplicate by photon correlation spectroscopy (PCS; Malvern HPPS5001, Herrenberg, Germany). The HD were slightly increased to $21 \mathrm{~nm}$ and $85 \mathrm{~nm}$ (polydispersity index 0.18 ) according to the S-TPP coating - see Table 2 - and a very small fraction of agglomerates (when AuNP volume and not the intensity was plotted the fraction of agglomerates disappeared; data not shown). Zeta potential of the radiolabeled ${ }^{198} \mathrm{AuNP}$ was measured in a distilled water suspention as used for rat application; 15 cycles, 10 runs, for each sample in triplicate (ZetaPals, Brookhaven Instruments). For other AuNP parameters see Table 2. The 1.4 nm AuNP solution and the $18 \mathrm{~nm}$ AuNP suspensions remained stable during at least two weeks without any detectable precipitation or change of color. Due to gravitational sedimentation $80 \mathrm{~nm}$ AuNP settled during two weeks but could be re-dispersed by vortexing into the same pink suspension as before.

\section{Animals}

Twenty-four healthy, adult female Wistar-Kyoto rats (WKY/Kyo@Rj rats, Janvier, Le Genest Saint Isle, France), 3-4 months of age and about $250 \mathrm{~g}$ body weight (BW) prior to pregnancy,) were used in these studies; twelve of which were pregnant and were enclosed into the experimental protocol on day $18 \pm 1$ of gestation $\left(3^{\text {rd }}\right.$ trimester); All rats were housed in pairs in humidity- and temperature-controlled ventilated cages on a $12 \mathrm{~h}$ day/ night cycle prior to the experiments. A rodent diet and water were provided ad libitum. Groups of four pregnant rats or four non-pregnant controls were randomly assigned to the IV administration of the three different-sized ${ }^{198}$ AuNP. The in-vivo biodistribution studies were conducted under German federal guidelines for the use and care of laboratory animals and were approved by the Regierung von Oberbayern (Government of District of Upper Bavaria, Approval No. 211-2531-94/04) and by the Institutional Animal Care and Use Committee of the Helmholtz Zentrum München - German Research Center for Environmental Health.

\section{${ }^{198}$ AuNP administration and analysis of ${ }^{198}$ AuNP biodistribution}

Colloidal suspensions of $1.4,18$ or $80 \mathrm{~nm}{ }^{198}$ AuNP were slowly injected into the tail vein of pregnant rats or nonpregnant controls [4,10]. For $1.4 \mathrm{~nm}$ and $18 \mathrm{~nm}$ ${ }^{198} \mathrm{AuNP}$ doses of about $5 \mu \mathrm{g}$ per rat were chosen and $25 \mu \mathrm{g}$ per rat of the $80 \mathrm{~nm}{ }^{198} \mathrm{AuNP}$, respectively. Rats were anesthetized by inhalation of $3-5 \%$ isoflurane until muscular tonus relaxed. A suspension volume of $130 \mu \mathrm{L}$ 
containing ${ }^{198}$ AuNP was placed at the lower end of a 1mL-insulin-syringe without any air at the tip of the syringe. A flexible intravenous catheter (diameter 24G) was placed into the tail vein. Initially, $100 \mu \mathrm{L}$ phosphate buffered saline (PBS) was injected testing for controlling adequate positioning of the catheter in the tail vein before the syringe with the ${ }^{198}$ AuNP suspension was connected and the suspension was slowly injected during about 30 seconds. The dead space in the syringe and connector had been determined to be $80 \mu \mathrm{L}$ such that a dose of $50 \mu \mathrm{L}$ ${ }^{198} \mathrm{AuNP}$ suspension was injected into the tail vein. In Table 2 the ${ }^{198}$ AuNP doses in terms of gold mass, surface and numbers are given for all three sizes.

Twenty-four hours after ${ }^{198}$ AuNP administration the rats were killed by exsanguinations cannulating the abdominal aorta and aspirating blood with a syringe under deep anesthesia by continuous isoflurane inhalation (3-5\%) until death. About 70\% of the blood volume was sampled via the abdominal aorta as estimated from the blood volume and BW. As described earlier $[61,62]$ all organs including the uterus with all amnions and fetuses and tissues of interest, the entire remaining carcass and the total excreta during 24 hours were weighed in wet state and stored for radio-analysis. While non-pregnant controls were housed singly in metabolic cages and urinary and fecal excreta were collected separately, the pregnant rats were kept in normal cages to avoid any stress and fecal droppings were manually separated from the bedding with the urine for separate radioanalysis. To avoid any cross contamination, no organs were cut open and all body fluids were sampled immediately via cannulation of vessels or excretory ducts before cutting. Hence, the following samples were radio-analyzed:

- Uterus: (a) for non-pregnant rats the uterus was one sample; (b) for pregnant rats there were four compartments: (i) the uterine wall, (ii) the placentas together with all umbilical cords and amniotic sacs, (iii) the total of all amniotic fluids which were collected by cannulating each amnion and (iv) the total of all fetuses; these four compartments of each rat were radio-analyzed.

- Other organs: lungs, liver, spleen, kidneys, brain, heart, total exsanguinated blood, gastro-intestinal tract (GIT) including: esophagus, stomach, small and large intestine;

- Tissues: total skin, sample of muscle, sample of bone: femur; the injection site of the tail was separated;

- Remainder: total remaining carcass beyond the listed organs and tissues;

- Excretion: total urine and feces, collected separately.

Without any additional preparatory step all samples were radio-analyzed for ${ }^{198} \mathrm{Au}$ content.

\section{A complete balance of ${ }^{198} \mathrm{Au}$ radioactivity}

A complete balance of ${ }^{198} \mathrm{Au}$ radioactivity retained in the body and cleared by excretion out of the body was quantified by gamma-spectroscopy in either a 10-mLwell-type $\mathrm{NaI}(\mathrm{Tl})$ scintillation detector for small samples $(<3 \mathrm{~g})$ or a 1-L-well-type $\mathrm{NaI}(\mathrm{Tl})$ scintillation detector for large samples like the remaining carcass $[61,63]$ thoroughly lead-shielded for reduction of background radiation. From measured count rates, corrected for background and radioactive decay and calibrated with a well-defined ${ }^{198} \mathrm{Au}$ source, amounts of radioactivity at reference date were calculated. Samples yielding net counts (i.e. background-corrected counts) in the photopeak region-of-interest of the ${ }^{198} \mathrm{Au}$ gamma spectrum were defined to be below the detection limit when they were less than three standard deviations of the background counts of this region-of-interest. Therefore, calculated amounts of radioactivity are directly proportional to the mass of ${ }^{198} \mathrm{AuNP}$. The sum of all ${ }^{198} \mathrm{Au}$ amounts of radioactivity was compared to the administered dose as determined by radio analysis of an aliquot of the administered ${ }^{198}$ AuNP solution. Hence, total radioactivity equals the administered radioactivity per rat to which ${ }^{198} \mathrm{Au}$ radioactivity of each sample was normalized as a fraction.

\section{Statistical analysis}

For statistical data analysis Graph pad prism 4.0 was used. All calculated significances are based on a one-way analysis of variance (ANOVA) followed either by a post hoc Tukey test or post hoc Sidak test as indicated in the Figure legends. In case of an individual two-group comparison, the unpaired $t$ test was used.

\section{Additional file}

Additional file 1: Characterization of the physico-chemical parameters.

\section{Competing interests}

All authors declare no competing financial interests.

\section{Authors' contributions}

Study design: MSB, WGK, GO. Study performance and AuNP preparation: MSB, WGK, GS, JL, AW, MS. Data evaluation and analysis including statistics: MSB, WGK, AW, MS, FT, SH. Manuscript editing: MSB, WGK, GO, MS, FT, JL, GS. All authors read and approved the final manuscript.

\section{Authors' information}

MSB: ${ }^{5}$ Current address: Bavarian Health and Food Safety Authority, 85764 Oberschleissheim, Germany.

SH: ${ }^{6}$ Current address: Walter Brendel Centre of Experimental Medicine, Ludwig-Maximilians-Universität München, Munich, Germany.

FT: ${ }^{7}$ Current address: FOCAS institute, Dublin Institute of Technology, Dublin, Irland.

\section{Acknowledgements}

We thank Dr. Carsten Rudolph from the Dr. von Hauner Children's Hospital, Ludwig-Maximillian-University of Munich, for his support of the zeta potential measurements. In addition, we are very grateful to Dr. Dorothea Alber and 
Gregor Bukalis, Helmholtz Center Berlin, for careful neutron irradiations of the various AuNP samples in the nuclear research reactor

This work was partially supported from the German Research Foundation FOR 627 and SPP 1313, from EU-FP6 project Particle-Risk (012912 (NEST)); from EU FP7 projects NeuroNano (NMP4-SL-2008-214547) and ENPRA (NMP4-SL-2009-228789); from the Air Force Office of Scientific Research/U.S. Dept. of Defense MURI Grant FA9550-04-1-0430 and the NIEHS Center Grant P30 ESO1247.

\section{Author details}

'Institute of Lung Biology and Disease, Helmholtz Zentrum München German Research Center for Environmental Health, 85764 Neuherberg/ Munich, Germany. ${ }^{2}$ Department of Environmental Medicine, University of Rochester, Rochester, New York, USA. ${ }^{3}$ Institute of Inorganic Chemistry University Duisburg-Essen, 45117 Essen, Germany. ${ }^{4}$ Institute of Epidemiology II, Helmholtz Zentrum München - German Research Center for Environmental Health, 85764 Neuherberg/Munich, Germany. ${ }^{5}$ Current address: Bavarian Health and Food Safety Authority, 85764 Oberschleissheim, Germany. ${ }^{6}$ Current address: Walter Brendel Centre of Experimental Medicine, Ludwig-Maximilians-Universität München, Munich, Germany. ${ }^{7}$ Current address: Focus Research Institute, Dublin Institute of Technology, Dublin, Ireland.

Received: 11 March 2014 Accepted: 16 July 2014

Published online: 10 September 2014

\section{References}

1. Oberdörster G, Oberdörster E, Oberdörster J: Nanotoxicology: An Emerging Discipline Evolving from Studies of Ultrafine Particles. Environ Health Perspect 2005, 113:823-839.

2. Mills NL, Amin N, Robinson SD, Anand A, Davies J, Patel D, de la Fuente JM, Cassee FR, Boon NA, Macnee W, Millar AM, Donaldson K, Newby DE: Do inhaled carbon nanoparticles translocate directly into the circulation in humans? Am J Respir Crit Care Med 2006, 173:426-431.

3. Kreyling WG, Semmler-Behnke M, Seitz J, Scymczak W, Wenk A, Mayer P, Takenaka S, Oberdorster G: Size dependence of the translocation of inhaled iridium and carbon nanoparticle aggregates from the lung of rats to the blood and secondary target organs. Inhal Toxicol 2009, 21(Suppl 1):55-60.

4. Lipka J, Semmler-Behnke M, Sperling RA, Wenk A, Takenaka S, Schleh C, Kissel T, Parak WJ, Kreyling WG: Biodistribution of PEG-modified gold nanoparticles following intratracheal instillation and intravenous injection. Biomaterials 2010, 31:6574-6581.

5. Schleh C, Semmler-Behnke M, Lipka J, Wenk A, Hirn S, Schaffler M, Schmid G, Simon U, Kreyling WG: Size and surface charge of gold nanoparticles determine absorption across intestinal barriers and accumulation in secondary target organs after oral administration. Nanotoxicology 2012, 6:36-46.

6. Hirn S, Semmler-Behnke M, Schleh C, Wenk A, Lipka J, Schaffler M, Takenaka S, Moller W, Schmid G, Simon U, Kreyling WG: Particle size-dependent and surface charge-dependent biodistribution of gold nanoparticles after intravenous administration. Eur J Pharm Biopharm 2010, 77:407-416

7. Wiebert P, Sanchez-Crespo A, Falk R, Philipson K, Lundin A, Larsson S, Moller W, Kreyling WG, Svartengren M: No significant translocation of inhaled 35-nm carbon particles to the circulation in humans. Inhal Toxicol 2006, 18:741-747.

8. Wiebert P, Sanchez-Crespo A, Seitz J, Falk R, Philipson K, Kreyling WG, Moller W, Sommerer K, Larsson S, Svartengren M: Negligible clearance of ultrafine particles retained in healthy and affected human lungs. Eur Respir J 2006, 28:286-290

9. Möller W, Felten K, Sommerer K, Scheuch G, Meyer G, Meyer P, Haussinger $K$, Kreyling WG: Deposition, retention, and translocation of ultrafine particles from the central airways and lung periphery. Am J Respir Crit Care Med 2008, 177:426-432.

10. Semmler-Behnke M, Kreyling WG, Lipka J, Fertsch S, Wenk A, Takenaka S, Schmid G, Brandau W: Biodistribution of 1.4- and 18-nm gold particles in rats. Small 2008, 4:2108-2111.

11. Kreyling WG, Hirn S, Möller W, Schleh C, Wenk A, Celik G, Lipka J, Schäffler M, Haberl N, Johnston BD, Sperling R, Schmid G, Simon U, Parak WJ, Semmler-Behnke M: Air-Blood Barrier Translocation of Tracheally Instilled Gold Nanoparticles Inversely Depends on Particle Size. ACS Nano 2013, 8:222-223.
12. Rinderknecht A, Prudhomme R, Poreda R, Gelein R, Corson N, Pidruczny A Finkelstein J, Oberdörster G, Elder A: Biokinetics of AU nanoparticles relative to size surface coating and portal of entry. In 47th Annual Society of Toxicology Meeting; Seattle, WA.; 2008.

13. Schweitzer AD, Revskaya E, Chu P, Pazo V, Friedman M, Nosanchuk JD, Cahill S, Frases S, Casadevall A, Dadachova E: Melanin-Covered Nanoparticles for Protection of Bone Marrow During Radiation Therapy of Cancer. Int J Radiat Oncol Biol Phys 2010, 78(5):1494-1502.

14. Fuchs $R$, Ellinger I: Endocytic and transcytotic processes in villous syncytiotrophoblast: role in nutrient transport to the human fetus. Traffic 2004, 5:725-738

15. Takeda K, Suzuki Kl, Ishihara A, Kubo-Irie M, Fujimoto R, Tabata M, Oshio S, Nihei $Y$, Ihara T, Sugamata M: Nanoparticles Transferred from Pregnant Mice to Their Offspring Can Damage the Genital and Cranial Nerve Systems. J Health Sci 2009, 55:95-102.

16. Sugamata M, Ihara T, Sugamata M, Takeda K: Maternal exposure to diesel exhaust leads to pathological similarity to autism in newborns. J Health Sci 2006, 52:486-488.

17. Sugamata M, Ihara T, Takano H, Oshio S, Takeda K: Maternal diesel exhaust exposure damages newborn murine brains. J Health Sci 2006, 52:82-84.

18. Ritz B, Wilhelm M, Hoggatt KJ, Ghosh JK: Ambient air pollution and preterm birth in the environment and pregnancy outcomes study at the University of California, Los Angeles. Am J Epidemiol 2007, 166:1045-1052.

19. Coggins CRE, Ayres PH, Mosberg AT, Sagartz JW, Hayes AW: Subchronic Inhalation Study in Rats Using Aged and Diluted Sidestream Smoke from a Reference Cigarette. Inhal Toxicol 1993, 5:77-95.

20. Witschi H, Lundgaard SM, Rajini P, Hendrickx AG, Last JA: Effects of exposure to nicotine and to sidestream smoke on pregnancy outcome in rats. Toxicol Lett 1994, 71:279-286.

21. Gospe SM Jr, Zhou SS, Pinkerton KE: Effects of environmental tobacco smoke exposure in utero and/or postnatally on brain development. Pediatr Res 1996, 39:494-498.

22. Wick P, Malek A, Manser P, Meili D, Maeder-Althaus X, Diener L, Diener PA, Zisch A, Krug HF, von Mandach U: Barrier Capacity of Human Placenta for Nanosized Materials. Environ Health Perspect 2010, 118:432-436.

23. Myllynen PK, Loughran MJ, Howard CV, Sormunen R, Walsh AA, Vahakangas $\mathrm{KH}$ : Kinetics of gold nanoparticles in the human placenta. Reprod Toxicol 2008, 26:130-137.

24. Yamashita K, Yoshioka Y, Higashisaka K, Mimura K, Morishita Y, Nozaki M, Yoshida T, Ogura T, Nabeshi H, Nagano K, Abe Y, Kamada H, Monobe Y, Imazawa T, Aoshima H, Shishido K, Kawai Y, Mayumi T, Tsunoda S, Itoh N, Yoshikaw T, Yanagihara I, Saito S, Tsutsumi Y: Silica and titanium dioxide nanoparticles cause pregnancy complications in mice. Nat Nanotechnol 2011, 6:321-328

25. Keelan JA: Nanotoxicology: Nanoparticles versus the placenta. Nat Nanotechnol 2011, 6:263-264.

26. Rattanapinyopituk K, Shimada A, Morita T, Sakurai M, Asano A, Hasegawa T, Inoue K, Takano H: Demonstration of the Clathrin- and Caveolin-Mediated Endocytosis at the Maternal-Fetal Barrier in Mouse Placenta after Intravenous Administration of Gold Nanoparticles. J Vet Med Sci 2013, 76:377-387.

27. Ockleford CD, Whyte A: Differeniated regions of human placental cell surface associated with exchange of materials between maternal and foetal blood: coated vesicles. J Cell Sci 1977, 25:293-312

28. Ockleford CD, Whyte A, Bowyer DE: Variation in the volume of coated vesicles isoalted from human placenta. Cell Biol Int Rep 1977, 1:137-146.

29. Kertschanska S, Kosanke G, Kaufmann P: Pressure dependence of so-called transtrophoblastic channels during fetal perfusion of human placental villi. Microsc Res Tech 1997, 38:52-62.

30. Kertschanska S, Stulcova B, Kaufmann P, Stulc J: Distensible transtrophoblastic channels in the rat placenta. Placenta 2000, 21:670-677.

31. Knipp GT, Audus KL, Soares MJ: Nutrient transport across the placenta. Adv Drug Deliv Rev 1999, 38:41-58.

32. Schmid G: The relevance of shape and size of Au55 clusters. Chem Soc Rev 2008, 37:1909-1930.

33. King BF: A cytological study of plasma membrane modifications, intercellular junctions, and endocytic activity of amniotic epithelium. Anat Rec 1978, 190:113-125.

34. Modena AB, Fieni S: Amniotic fluid dynamics. Acta Biomed 2004 75(Suppl 1):11-13.

35. Saunders M: Transplacental transport of nanomaterials. Wiley Interdiscip Rev Nanomed Nanobiotechnol 2009, 1:671-684 
36. Sadauskas E, Jacobsen NR, Danscher G, Stoltenberg M, Vogel U, Larsen A Kreyling W, Wallin $\mathrm{H}$ : Biodistribution of gold nanoparticles in mouse lung following intratracheal instillation. Chem Central J 2009, 3:16

37. Workshop IRSI: The relevance of the rat lung response to particle overload for human risk assessment: A workshop consensus report. Inhal Toxicol 2000, 12:1-17.

38. Conner SD, Schmid SL: Regulated portals of entry into the cell. Nature 2003, 422:37-44.

39. Pan Y, Leifert A, Ruau D, Neuss S, Bornemann J, Schmid G, Brandau W, Simon U, Jahnen-Dechent W: Gold Nanoparticles of Diameter $1.4 \mathrm{~nm}$ Trigger Necrosis by Oxidative Stress and Mitochondrial Damage. Small 2009, 5:2067-2076.

40. Lundqvist M, Stigler J, Elia G, Lynch I, Cedervall T, Dawson KA: Nanoparticle size and surface properties determine the protein corona with possible implications for biological impacts. Proc Natl Acad Sci U S A 2008 , 105:14265-14270

41. Lynch I, Dawson KA: Protein-nanoparticle interactions. Nano Today 2008, 3:40-47.

42. Monopoli MP, Walczyk D, Campbell A, Elia G, Lynch I, Baldelli Bombelli F, Dawson KA: Physical-Chemical Aspects of Protein Corona: Relevance to in Vitro and in Vivo Biological Impacts of Nanoparticles. J Am Chem Soc 2010, 1-10.

43. Schäffler M, Sousa F, Wenk A, Sitia L, Hirn S, Schleh C, Haberl N, Violatto M, Canovi M, Andreozzi P, Salmona M, Bigini P, Kreyling WG, Krol S: Blood protein coating of gold nanoparticles as potential tool for organ targeting. Biomaterials 2014, 35:3455-3466.

44. Cheung CY, Brace RA: Amniotic fluid volume and composition in mouse pregnancy. J Soc Gynecol Investig 2005, 12:558-562.

45. Robertson P, Faber JJ, Brace RA, Louey S, Hohimer AR, Davis LE, Anderson DF: Responses of amniotic fluid volume and its four major flows to lung liquid diversion and amniotic infusion in the ovine fetus. Reprod Sci 2009, 16:88-93.

46. Underwood MA, Gilbert WM, Sherman MP: Amniotic Fluid: Not Just Fetal Urine Anymore. J Perinatol 2005, 25:341-348.

47. Lutz HG: Clusters and Colloids. From Theory to Applications. New York: VCH Verlagsgesellschaft, Weinheim/NCH Publishers; 1995.

48. Tominaga T, Tenma S, Watanabe H, Giebel U, Schmid G: Tracer Diffusion of a Ligand-Stabilized Two-Shell Gold Cluster. Chem Lett 1996, 25:1033-1034.

49. Möller W, Gibson N, Geiser M, Pokhrel S, Wenk A, Takenaka S, Schmid O, Bulgheroni A, Simonelli F, Kozempel J, Holzwarth U, Wigge C,

Eigeldinger-Berthou S, Mädler L, Kreyling W: Gold nanoparticle aerosols for rodent inhalation and translocation studies. J Nanoparticle Res 2013, 15:1-13.

50. Semmler-Behnke M, Kreyling WG, Schulz H, Takenaka S, Butler JP, Henry FS, Tsuda A: Nanoparticle delivery in infant lungs. Proc Natl Acad Sci U S A 2012, 109:5092-5097.

51. Hainfeld JF, O'Connor MJ, Dilmanian FA, Slatkin DN, Adams DJ, Smilowitz HM: Micro-CT enables microlocalisation and quantification of Her2targeted gold nanoparticles within tumour regions. Br J Radiol 2011 84:526-533.

52. Khlebtsov N, Dykman L: Biodistribution and toxicity of engineered gold nanoparticles: a review of in vitro and in vivo studies. Chem Soc Rev 2011, 40:1647-1671.

53. Paciotti GF, Myer L, Weinreich D, Goia D, Pavel N, McLaughlin RE, Tamarkin L: Colloidal gold: a novel nanoparticle vector for tumor directed drug delivery. Drug Deliv 2004, 11:169-183.

54. Kim Y, Lobatto ME, Kawahara T, Lee Chung B, Mieszawska AJ, Sanchez-Gaytan BL, Fay F, Senders ML, Calcagno C, Becraft J, Tun Saung M, Gordon R, Stroes ES, Ma M, Farokhzad OC, Fayad ZA, Mulder WJ, Langer R: Probing nanoparticle translocation across the permeable endothelium in experimental atherosclerosis. Proc Natl Acad Sci U S A 2014, 111:1078-1083.

55. Mieszawska AJ, Kim Y, Gianella A, van Rooy I, Priem B, Labarre MP, Ozcan C, Cormode DP, Petrov A, Langer R, Farokhzad OC, Fayad ZA, Mulder WJ: Synthesis of polymer-lipid nanoparticles for image-guided delivery of dual modality therapy. Bioconjug Chem 2013, 24:1429-1434.

56. Harisinghani MG, Barentsz J, Hahn PF, Deserno WM, Tabatabaei S, van de Kaa $\mathrm{CH}$, de la Rosette J, Weissleder R: Noninvasive detection of clinically occult lymph-node metastases in prostate cancer. N Engl J Med 2003, 348:2491-2499.

57. Lobatto ME, Fuster V, Fayad ZA, Mulder WJ: Perspectives and opportunities for nanomedicine in the management of atherosclerosis. Nat Rev Drug Discov 2011, 10:835-852.
58. McArdle HJ, Andersen HS, Jones H, Gambling L: Copper and Iron Transport Across the Placenta: Regulation and Interactions. J Neuroendocrino/ 2008, 20:427-431

59. Turkevitch J, Stevenson PC, Hillier J: A study of the nucleation and growth processes in the synthesis of colloidal gold. Discuss Faraday Soc 1951, 11:55-75.

60. Schmid G, Lehnert A: The Complexation of Gold Colloids. Angew Chem Int Ed 1989, 28:780-781.

61. Semmler M, Seitz J, Erbe F, Mayer P, Heyder J, Oberdorster G, Kreyling WG: Long-term clearance kinetics of inhaled ultrafine insoluble iridium particles from the rat lung, including transient translocation into secondary organs. Inhal Toxicol 2004, 16:453-459.

62. Semmler-Behnke M, Takenaka S, Fertsch S, Wenk A, Seitz J, Mayer P, Oberdorster G, Kreyling WG: Efficient elimination of inhaled nanoparticles from the alveolar region: evidence for interstitial uptake and subsequent reentrainment onto airways epithelium. Environ Health Perspect 2007 115:728-733.

63. Kreyling WG, Semmler M, Erbe F, Mayer P, Takenaka S, Schulz H, Oberdörster G, Ziesenis A: Translocation of ultrafine insoluble iridium particles from lung epithelium to extrapulmonary organs is size dependent but very low. $J$ Toxico Environ Health-Part A 2002, 65:1513-1530.

doi:10.1186/s12989-014-0033-9

Cite this article as: Semmler-Behnke et al:: Size dependent translocation and fetal accumulation of gold nanoparticles from maternal blood in the rat. Particle and Fibre Toxicology 2014 11:33.

\section{Submit your next manuscript to BioMed Central and take full advantage of:}

- Convenient online submission

- Thorough peer review

- No space constraints or color figure charges

- Immediate publication on acceptance

- Inclusion in PubMed, CAS, Scopus and Google Scholar

- Research which is freely available for redistribution

Submit your manuscript at www.biomedcentral.com/submit
C Biomed Central 